\title{
PROCESS OPTIMIZATION AND PERFORMANCE EVALUATION OF A DOWNDRAFT GASIFIER FOR ENERGY GENERATION FROM WOOD BIOMASS
}

\author{
Ilesanmi Daniyan ${ }^{a, *}$, Felix Ale $^{b}$, Ikenna Damian Ulhegbu ${ }^{c}$, \\ Kazeem Bello $^{d}$, Момоh Osazele ${ }^{c}$ \\ a Tshwane University of Technology, Department of Industrial Engineering, Staatsartillerie Road, Private Bag \\ X680, Pretoria 0001, South Africa \\ ${ }^{b}$ National Space Research $\& 5$ Development Agency, Department of Engineering and Space Systems, Abuja, Nigeria \\ ${ }^{c}$ Afe Babalola University, Department of Mechanical $\&$ Mechatronics Engineering, P. M. B. 5454, Ado Ekiti, \\ Nigeria \\ ${ }^{d}$ Federal University, Oye-Ekiti, Department of Mechanical Engineering, Oye-Are Road, Oye-Ekiti, Nigeria \\ * corresponding author: afolabiilesanmi@yahoo.com
}

\begin{abstract}
In recent time, due to the increasing demand for energy and the need to address environment-related issues, a great deal of focus has been given to alternative sources of energy, which are green, sustainable and safe. This work considers the process optimization and performance evaluation of a downdraft gasifier, suitable for energy generation using wood biomass. The assessment of the performance of the downdraft gasifier was based on the amount of output energy generated as well as the emission characteristics of the output. The Response Surface Methodology (RSM) was employed for the determination of the optimum range of the process parameters that will yield the optimum conversion of the biomass to energy. The optimum process parameters that produced the highest rate of conversion of biomass to energy $\left(2.55 \mathrm{Nm}^{3} / \mathrm{kg}\right)$ during the physical experiments were: temperature $\left(1000^{\circ} \mathrm{C}\right)$, particle size $(6.0 \mathrm{~mm})$ and residence time $(35 \mathrm{~min})$. The produced gas indicated an appreciable generation of methane gas $(10.04 \%$ vol. $)$, but with a significant amount of CO $(19.20 \%$ vol.) and $\mathrm{CO}_{2}(22.68 \%$ vol.). From the numerical results obtained, the gas yield was observed to increase from $1.86908 \mathrm{Nm}^{3} / \mathrm{kg}$ to $2.40324 \mathrm{Nm}^{3} / \mathrm{kg}$ as the temperature increased from $800{ }^{\circ} \mathrm{C}$ to $1200{ }^{\circ} \mathrm{C}$. The obtained results indicate the feasibility for the production of combustible gases from the developed system using wood chips. It is envisaged that the findings of this work will assist in the development of an alternative and renewable energy source in an effort to meet the growing energy requirements.
\end{abstract}

KEYworDs: Downdraft gasifier, energy, RSM, optimization, wood biomass.

\section{INTRODUCTION}

Biomass resources are renewable sources of energy, which produce combustible fuels as a means of energy from organic materials, such as crop residues, wood chips, food or animal wastes [1-3]. Several researchers have proven that the development of sustainable energy resources is a catalyst for the development of any nation [4, 5]. Renewable sources of energy can be in the form of wind, solar, photovoltaic, hydropower, biomass, geothermal etc. [6]. The use of biomass as solid fuels for energy generation is predominant in African countries, especially for domestic applications such as cooking [7, 8]. The increasing global demand for energy can be linked to the increasing population, especially in the African continent, where the population number is experiencing an exponential growth. Biomass is a major resource for developing countries, but there is an over-reliance on the use of traditional biomass for energy generation in the African continent, which poses a significant health risk [9, 10. A recent study estimates the number of people who rely on biomass solid fuels to be 700 million people in Sub-
Saharan Africa [11. This can be attributed to the lack of modern energy facilities and the proximity to biomass resources in the rural communities as well as the cost of the solid biomass fuel etc. Over the years, biomass resources have been used for energy generation because it is cost effective, readily available, easily accessible, renewable and easy to store [9 11]. Wood is one of the primary biomass resources used for energy generation. Researches have proven that, in the traditional process of wood combustion, only partial utilization of the energy inherent in the wood biomass takes place, with some energy lost into the environment in the form of emissions. The modern process of harnessing energy from wood biomass via the process of gasification involves the collection of the emission and its combustible components, to minimize the energy losses during the conversion process [12 14.

Furthermore, the traditional way of harnessing energy from wood biomass causes environmental and indoor pollution due to the generated emissions, depending on the usage, population density, location 
and the layout of the environment where it is harnessed [15, 16]. This is because the heat energy produced from the incomplete combustion of the solid fuel generate gases due to a limited presence of oxygen during the combustion reaction [17]. If not controlled, such emissions pose a great health risk as studies have revealed that many health challenges and deaths can be attributed to it [18, 19. A properly designed gasifier can suitably convert solid fuels such as wood chips into safe gaseous fuels. The energy generated via the gasification of wood biomass is suitable for domestic use, powering stationary gasoline engines, such as electric generators, pumps, and industrial equipment of light-to-medium duty. Modified gasoline engines can also be powered primarily via the energy from wood biomass [20. The generation of energy via the use of wood biomass boasts safety, environmental, social and economic benefits, if properly harnessed when compared to an energy generated through the traditional wood combustion process. Its environmental benefit stems from the fact the energy usage significantly reduces the net carbon emissions, thereby promoting a significant reduction in air pollution and global warming [21, 22]. By weight, the produced gas contains combustible elements and compounds, approximately $20 \%$ of carbon oxide (CO), $20 \%$ of hydrogen $(\mathrm{H})$, a certain amount of methane $\left(\mathrm{CH}_{4}\right)$, with about $55 \%$ of nitrogen $(\mathrm{N})$, which is not combustible, and other gaseous and solid matters such as moisture, sulphur, and ash [23]. The process of the wood combustion produces carbon dioxide $\left(\mathrm{CO}_{2}\right)$ and water vapour $\left(\mathrm{H}_{2} \mathrm{O}\right)$ as the products of combustion as well as carbon oxide (CO), a poisonous gas, as a by-product [24, 25].

The modern process of gasification is developed to ensure a complete transformation of the biomass constituents into clean gaseous fuels. However, in order to address the health risk posed by the continuous use of the traditional biomass for energy generation, there is a need for the development of an efficient system for the conversion of biomass into fuel. Many papers have been reported in this regard. For instance, Chingunwa et al. [26] developed a wood gasifier for powering an internal combustion engine. The gasifier operates in the combined heat and power modes for providing power and heat to domestic and industrial applications. The residence time and operating temperature are important factors, which determine the conversion rate of wood biomass into energy. Li et al. 22] investigated the behaviour of wood biomass under a high temperature application. The findings from this study revealed that there was a significant mass loss of biomass at an elevated temperature at the devolatilization stage while requiring a long residence time to drive the conversion process to completion. In addition, $\mathrm{Lu}$ et al. [7] investigated the effect of particle sizes and shapes, as well as the combustion characteristics of the wood particles on the combustion characteristics of the biomass using modelling techniques. The findings indicate that the particle size and shapes significantly affect the dynamics of the biomass particle, as well as the drying, heating and reaction rates. The authors reported an inverse relationship between the particle size and the drying, heating and reaction rates. Ingle and Lakade [27, reported on the design and development of a downdraft gasifier systems for the production of producer gas. The comparative analysis of the wood biomass with agricultural feedstock indicate that the wood biomass has a higher carbon oxide and hydrogen content as well as higher calorific value than the agricultural biomass briquettes. Masmoudi et al. 28, indicate that the temperature fields and the reactivity of the char affects the loading of the gasification process. In addition, the authors reported that another important factor that affects the yield of the hydrogen and carbon monoxide produced is the particle size of the biomass. Striugas et al. 29] performed an experimental analysis on the differences in the process parameters associated with the gasification process of lump and pelletized fuel. The authors found out that the major difference between these two types of feedstock include: the temperature of the gasification process, the pressure drop and the residual content. The gasification of feedstock of a larger size such as wood chips requires an elevated temperature, up to $1100^{\circ} \mathrm{C}$, as compared to waste and pellet biomass, which requires a maximum reaction temperature between $800-850{ }^{\circ} \mathrm{C}$.

The papers reviewed were able to establish the range of process parameters for the production of biogas. However, there is still a dearth of information regarding the process optimization of gasifier, hence, it is envisaged that this work will contribute to the existing knowledge on the production of clean producer gas for thermal domestic needs. The novelty of this work includes the process optimization and performance evaluation of an energy extraction through gasification using the Response Surface Methodology as well as the generation of design data for the development of a downdraft gasifier. The developed downdraft gasifier can serve as a template for scaling and future development. Furthermore, the process optimization through the use of numerical experimentation, validated via physical experiments, will assist in the determination of the feasible combination of the process parameters in order to keep them within the optimum range during the process of biomass conversion to fuel. In addition, the work provides a development framework for the production of energy from wood biomass. The focus of this study is to evaluate the performance of a wood gasifier, determine the optimum process parameters that will promote an efficient conversion of the wood chips (biomass) into energy and to analyse the composition (by volume percentage) of the gases produced by the downdraft gasifier. The following sections present the materials and method employed, results and discussion as well as conclusion and recommendation. 


\section{MATERIALS AND METHOD}

The design and construction of the downdraft gasifier had already been done and reported, this work is in line with the recommendation for a continuous performance evaluation of the system in terms of energy generation for powering small units in order to meet the thermal domestic needs. The section is divided into four sub-sections 2.1 2.4. The first sub-section presents the energy requirements and the thermal efficiency of the developed downdraft gasifier system, while the next sub-sections present the details of the conversion process of the wood biomass to energy. The third sub-section presents the optimization of the conversion process in order to obtain the most feasible combination of the process parameters that will produce the yield of gas while the last sub-section presents how the analysis of the composition of the produced gas was achieved.

\subsection{ENERGY REQUIREMENTS AND THERMAL EFFICIENCY}

The heating value of the gas produced is a function of the moisture content of the biomass. The lesser the moisture content, the higher is the energy content and vice versa. The moisture content can be determined on a dry basis as well as on a wet basis, as is expressed by Equation 130 .

$$
\text { M.C.dry }=\frac{\text { wet weight }- \text { dry weight }}{d r y \text { weight }} \times 100
$$

Where M.C.dry is the moisture content on a dry basis (\%).

The thermal efficiency of the system reduces with the amount of moisture content in the biomass and vice versa. This is due to the fact that there will be a heat loss during the drying and consequently, such an energy loss in the form of heat will no longer be available for the reduction reactions in the chemical bound energy in the gas. Therefore, the heating values increase with the reduction in the amount of moisture content and vice versa.

Equation 2 expresses the power output of the producer gas in the engine 31 .

$$
\begin{aligned}
& \text { Max. } \frac{\text { air }}{\text { gas }} \text { intake }=\frac{\frac{1}{2} \times N \times D}{60 \times 1000} \\
& \text { Max. } \frac{\text { air }}{\text { gas }} \text { intake }=0.045 \mathrm{~m}^{3} / \mathrm{s}
\end{aligned}
$$

Where $D$ is the outlet pipe diameter $(\mathrm{m}), N$ is the speed (in rpm), and the air/gas ratio (stoichiometric) is expressed as 1.1: 1.0

$$
\begin{aligned}
& \text { Max. gas intake }=\frac{1.0}{2.1} \times 0.045 \\
& \text { Max. gas intake }=0.0212 \mathrm{~m}^{3} / \mathrm{s}
\end{aligned}
$$

The real gas intake is expressed as Equation 5[31].

$$
\text { Real gas intake }=0.0212 \times f
$$

Where $f$ is the volumetric efficiency of the engine, which is a function of the engine's revolution per minute, as well as the design of the air inlet manifold of the engine.

If we consider revolutions to be $1500 \mathrm{rpm}$ and $f$ equal to 0.8 (for a well-designed and clean air inlet manifold), the real gas intake $\left(R_{g}\right)$ is given as:

$$
R_{g}=0.0212 \times 0.8=0.017 \mathrm{~m}^{3} / \mathrm{s}
$$

The thermal power $\left(P_{g}\right)$ in the gas is given as Equation 731 .

$$
P_{g}=R_{g} \times h_{v}
$$

Where $R_{g}$ is the real gas intake, which is calculated as $0.017 \mathrm{~m}^{3} / \mathrm{s}$, and $h_{v}$ is the heating value of the gas $\left(h_{v}\right)$ equal to $4800 \mathrm{~kJ} / \mathrm{m}^{3}$.

$$
\begin{gathered}
P_{g}=0.017 \times 4800=8.16 \mathrm{~kJ} / \mathrm{s} \\
P_{g}=81.6 \mathrm{~kW}
\end{gathered}
$$

The engine efficiency is partly a function of the compression ratio of the engine. Hence, for a compression ratio of $9.5: 1$, the efficiency $(\varepsilon)$ is estimated at $28 \%$.

Equations 9 and 11 express the maximum mechanical output of this engine as well as the maximum electrical output $(\cos \varphi$ generator $=0.80)$ respectively 31 .

$$
\begin{gathered}
P_{M} \max =P_{g} \times \varepsilon \\
P_{M} \max =81.6 \times 0.28=22.85 \mathrm{~kW} \\
P_{E} \max =P_{M} \max \times \cos \varphi \\
P_{E} \max =22.85 \times 0.80=18.30 \mathrm{kVA}
\end{gathered}
$$

By assumption, the thermal efficiency of the downdraft gasifier is considered to be $70 \%$, hence, the thermal power consumption (in kilowatts) is obtained from Equation 13

$$
T_{p}=\frac{P_{g}}{0.7}
$$

Recall $P_{c}=81.6 \mathrm{~kW}$, hence 


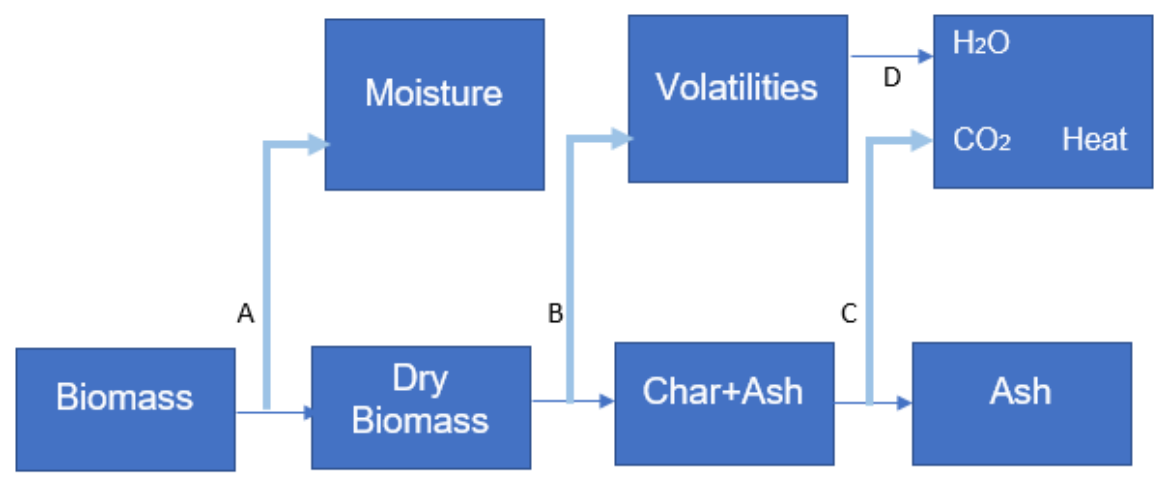

A (Drying), B (Devolatilization), C (Char oxidation), D (Volatile combustion)

Figure 1. The framework for the particle combustion during the conversion of wood biomass to energy [22].

$$
T_{p}=\frac{81.6}{0.7}=116.57 \mathrm{~kW}
$$

The heating value of biomass $\left(B_{H V}\right)$ was found to be $14 \%$ of the moisture content, which corresponds to $17000 \mathrm{~kJ} / \mathrm{kg}$. Therefore, the biomass consumption of the downdraft gasifier is expressed as Equation 15 [31.

$$
\begin{gathered}
G_{B C}=\frac{T_{P}}{B_{H V}} \\
G_{B C}=\frac{116.57}{17000}=0.0069 \mathrm{~kg} / \mathrm{s}= \\
=0.0069 \times 3600=24.84 \mathrm{~kg} / \mathrm{h}
\end{gathered}
$$

Therefore,

$$
\frac{G_{B C}}{P_{E} \max }
$$

$\frac{24.84}{18.30}=1.36 \mathrm{~kg}$ biomass produces $1 \mathrm{kWh}$ of electricity.

The yield of the gas produced is defined as the ratio of the flow rate of the produced total inert free gas to the mass flow rate of dry and ash free value of feedstock [32, 33]. Equations 18 and 19 express the yield of the producer gas $\left(Y_{g}\right)$ and the cold gas efficiency $(C G E)$, respectively [31].

$$
\begin{gathered}
Y_{g}=\frac{\left(Q_{a i r} \times 79\right)}{\left(N_{2} \times B_{i}\right)} \\
C G E=\frac{\operatorname{syn}_{H V} \times Y_{g}}{B_{H V}}
\end{gathered}
$$

Where $Y_{g}$ is the yield of the producer gas $\left(\mathrm{Nm}^{3} / \mathrm{kg}\right)$, $Q_{a i r}$ is the quantity of the input air $\left(\mathrm{Nm}^{3} / \mathrm{h}\right), B_{i}$ is the biomass input $(\mathrm{kg} / \mathrm{h}), N_{2}$ is the nitrogen mass fraction of the output gas, $C G E$ is the cold gas efficiency (\%), $S y n_{H V}$ is the lower heating value of the sync gas on a dry basis $\left(\mathrm{kJ} / \mathrm{Nm}^{3}\right)$ and $B_{H V}$ is the lower heating value of the biomass $(\mathrm{kJ} / \mathrm{kg})$.

\subsection{Conversion OF WOOD BIOMASS TO ENERGY}

The prototype unit in this work operates well on wood chips (minimum size: $0.019 \times 0.019 \times 0.008 \mathrm{~m}$ ) and blocks (up to $0.051 \mathrm{~m}^{3}$ ). The restriction in the size of the wood chips is to prevent a bridging of the wood chips. However, larger wood chip sizes could be used, if the fire tube diameter is increased. The choice of wood chips as a biomass resource stems from the fact it has several advantages. First, wood is suitable for energy generation. In addition, the ash content is usually significantly low, ranging between 0.5 to $2 \%$ by weight when properly harnessed; although this depends on the nature of the wood [34]. Furthermore, wood is sulphur free, hence, the use will contribute less to the environmental pollution with a lesser tendency to cause corrosion damage to the engine. In addition, wood is readily available, cost effective and its conversion process to energy is relatively simple. However, one of the major disadvantages for wood as a biomass resource is its moisture content. The moisture content and other volatile matters first have to be reduced significantly in the process of drying before being used for the energy generation.

The framework for the wood particle combustion during the conversion of wood biomass to energy is shown in Figure 1. The process of converting the biomass, in this case, the wood particles to generate energy (producer gas) is known as gasification. As depicted in Figure 1 there are about four major processes involved, namely: drying, pyrolysis, combustion and gasification processes [22, 35].

The process of converting a solid biomass fuel into energy is divided into these phases;

(1.) First is the feeding of the wood chips into the drying chamber through the hopper, followed by the drying process.

(2.) The process of drying is aimed at removing the moisture content in the biomass fuel up to $10 \%$ at a temperature of $150^{\circ} \mathrm{C}$. 


\begin{tabular}{llrrr}
\hline \multirow{2}{*}{ Notation } & Independent Variables & \multicolumn{3}{c}{ Levels } \\
\cline { 3 - 5 } & & \multicolumn{1}{c}{0} & 1 \\
\hline $\mathrm{A}$ & Temperature $\left({ }^{\circ} \mathrm{C}\right)$ & 800 & 1000 & 1200 \\
$\mathrm{~B}$ & Particle size $(\mathrm{mm})$ & 2 & 6 & 10 \\
$\mathrm{C}$ & Residence time $(\mathrm{min})$ & 10 & 35 & 60 \\
\hline
\end{tabular}

TABLE 1. Summary of the numerical experiments.

(3.) The pyrolysis process (devolatilization) usually occurs between $200-300^{\circ} \mathrm{C}$. This is aimed at removing other volatile matters from the already dried biomass to produce the mixture of ash and char. The pyrolysis process is a function of the biomass properties and determines the composition of the char, which subsequently undergoes the combustion reactions. The combustion process occurs when the volatile products and part of the produced char react in the presence of oxygen to form primarily oxides of carbon ( $\mathrm{CO}$ and $\left.\mathrm{CO}_{2}\right)$. This reaction is oxidative and produces heat (exothermic in nature), which is subsequently used for firing the dry mass and the mixture of char and ash during the conversion process. The gasification process occurs when the produced char reacts with steam to produce hydrogen and $\mathrm{CO}$. A further reaction of the $\mathrm{CO}$ with the steam promotes the forward reaction in a gasifier, producing $\mathrm{CO}_{2}$ and hydrogen. In addition, the presence of a limited amount of oxygen in the reaction chamber will promote a combustion reaction of some organic material to produce $\mathrm{CO}_{2}$ and energy. Methane and excess carbon dioxide are produced when $\mathrm{CO}_{2}$ and residual water react in the presence of a catalyst [36] according to Equation 20.

$$
4 \mathrm{CO}+2 \mathrm{H}_{2} \mathrm{O} \rightarrow \mathrm{CH}_{4}+3 \mathrm{CO}_{2}
$$

The ash containing a small quantity of unreacted carbon is collected in the gasifier grate.

From the design calculations, $2 \mathrm{~kg}$ of biomass was fed through the hopper into the downdraft gasifier having a nominal thermal capacity of $81.6 \mathrm{~kW}$, along with $0.5 \mathrm{~kg}$ of charcoal to activate the process of ignition. The system is periodically refilled before it is completely empty, and occasionally, the ashes are shaken down from the grate. It is necessary to cover the hopper when the downdraft gasifier unit is shut down, to prevent a wood combustion due to the entrance of air into the hopper. The downdraft gasifier unit can be shut down by turning off the ignition switch followed by the opening of the carburettor's air control valve for few seconds so to relieve any pressure from the system. Then, the air control valve is completely closed with the fuel hoper covered tightly. The producer gas passes through a two stage filtering process for cleaning, before it is used to drive the generator which produces the electricity. The generator is a spark ignited turbocharged vee configuration system which operates at $1500 \mathrm{rpm}$. The generator is a directly coupled system capable of delivering a 3phase voltage of $200 \mathrm{~V}$ at a frequency of $50 \mathrm{~Hz}$. As the engine burns the wood gas, the energy generated in the process is converted into kinetic energy. The generator then converts the kinetic energy, due to the rotation, into electricity.

\subsection{Optimization OF the CONVERSiOn PROCESS}

The optimization of the process parameters for the combustion process (char oxidation) was carried out using the Response Surface Methodology (RSM) with the process parameters selected in the following range: temperature $\left(800-1200^{\circ} \mathrm{C}\right)$, particle size $(2-10 \mathrm{~mm})$, residence time $(10-60 \mathrm{~min})$. The range of the process parameters was inspired by a similar work carried out by $\mathrm{Li}$ et al. 22 . Li et al. 22 reported on the prediction of a high-temperature rapid combustion behaviour of wood biomass particles using a modelling and simulation approach. However, the optimization of the process conditions was not reported. This is one of the focal points of this study in order to establish an optimum range of process parameters for the conversion of wood biomass to energy.

The choice of the RSM stems from the fact that it is suitable for the investigation of the interactive cross-effect of the process parameters as it affects the measured response (yield of the gas). It is also suitable for obtaining a predictive mathematical model for determining the yield of the gas as a function of the independent process parameters 38 .

The design expert software (version 8) containing the RSM was used for the design of the experiment and process optimization. The RSM gave feasible combinations of the process parameters, establishing 20 experimental runs, whose response (yield of the gas) was determined through physical experiments.

The summary of the experimental design, involving two factors varied over three levels: the high level $(+1)$, centre points $(0)$ and low level $(-1)$, is presented in Table 1

The validation of the numerical experiments was done via physical experiments as well as the Analysis of Variance (ANOVA). The indicators for determining the validity of a numerical experiments include the: "p-value Prob > F" (which should be less than 0.050), "Lack of Fit" (which should be statistically insignificant compared to the pure error) as well as the 


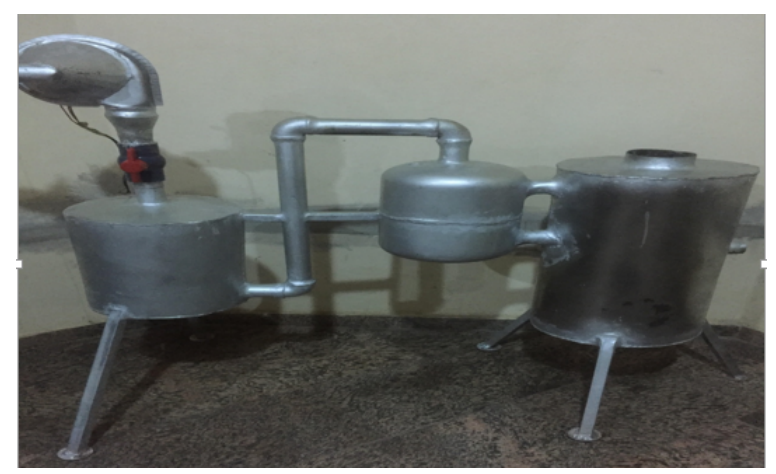

Figure 2. The developed downdraft gasifier [37].

\begin{tabular}{lc}
\hline Parameter & Specification \\
\hline Diameter of fire tube $(\mathrm{m})$ & 0.152 \\
Length of fire tube $(\mathrm{m})$ & 0.483 \\
Volume of hopper $\left(\mathrm{m}^{3}\right)$ & 0.15 \\
Height of nozzle $(\mathrm{m})$ & 0.107 \\
Diameter of nozzle $(\mathrm{m})$ & 0.0104 \\
Thermal consumption $(\mathrm{kW})$ & 116.57 \\
Biomass consumption $(\mathrm{kg} / \mathrm{h})$ & 24.84 \\
Pressure $(\mathrm{MPa})$ & 0.14 \\
\hline
\end{tabular}

TABLE 2. The design specifications of the developed downdraft gasifier.

correlation coefficients, namely the predicted $\mathrm{R}$ square, $\mathrm{R}$ squared and the adjusted R Squared (which should be close to 1) for a statistically significant model [39].

\subsection{AnAlysis of the COMPOSITION OF GAS PRODUCED}

A multi-component gas analyser (IR400) with five components, which feature Non-Dispersive Infrared (NDIR), Ultraviolent, VIS photometer, paramagnetic and electrochemical $\mathrm{O}_{2}$ and thermal conductivity sensors, was employed for measuring the gas components. The analyser coupled with the non-dispersed infrared sensor and probe was used for detecting the concentration of oxides of carbon as well as methane (hydrocarbon) in the gas sample in parts per million (ppm). The analyser has two separate analysis chambers (central interface), which is common for analyser modules. Following the automatic calibration of the analyser via a sample gas probe, the sample gas was fed into the analyser module at a room temperature through an inlet valve at a flow rate of 0.0000166 $\mathrm{m}^{3} / \mathrm{sec}$. The analyser module is a blind analysis unit, which measures the gas concentration with the results displayed with the aid of the liquid crystal display of the analyser. The results obtained in ppm were divided by 10,000 to obtain the concentration of the gas in volume percentage.

\section{Results AND Discussion}

This section comprises three sub sections (3.1 3.3), which present the results obtained from the physical experiments, numerical experiments as well as the results obtained from the analysis of the concentration of the gas produced.

\subsection{The Results obtained from the PHYSICAL EXPERIMENTS}

The developed downdraft gasifier is shown in Figure2 2

Table 2 presents the design specifications of the developed downdraft gasifier.

The results obtained from the proximate and ultimate analyses of the wood biomass used for the production of the gas and the percentage composition of the constituents of the produced gas are presented in Table 3 Generally, the producer gas obtained from biomass gasifiers contains some amount of tar. The higher the amount of tar present in the producer gas, the lesser is its suitability for fuel cells, engines and turbines. The tar content of the experiment has been measured and found to be within the permissible range, which further confirms the fact that the gasification technology was successfully implemented. The obtained results have been reported in Daniyan et al. [37.

The proximate analysis of the wood biomass in terms of the moisture content, volatile matters, ash and fixed carbon as presented in Table 3 is necessary for the determination of the heating value of the 


\begin{tabular}{lcc}
\hline Types of Analysis & Constituents of biomass/gas & \% Composition (wet basis) \\
\hline Proximate Analysis & Moisture & 10.03 \\
& Volatile matter & 48.85 \\
& Ash & 6.23 \\
& Fixed carbon & 38.15 \\
Types of Analysis & Constituents of biomass/gas & \% Composition (dry basis) \\
Ultimate Analysis & Carbon & 52.38 \\
& Hydrogen & 6.23 \\
& Oxygen & 21.43 \\
& Nitrogen & 0.60 \\
& Others & 0.40 \\
\hline
\end{tabular}

TABLE 3. The analysis of the wood biomass.

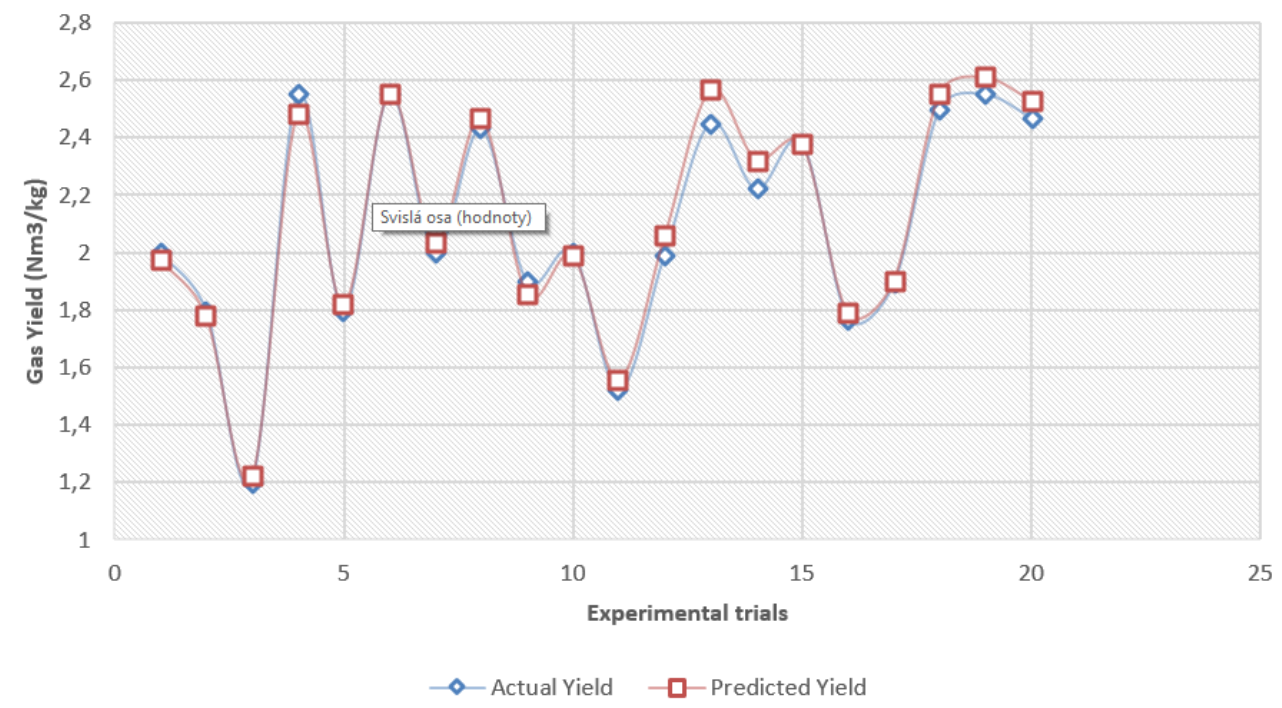

FigurE 3 . The plots of the actual and predicted yields of the gas produced.

biomass. Similarly, the ultimate analysis evaluates the chemical composition of the biomass and this is useful in the process design for an optimum rate of conversion of the biomass to energy.

\subsection{The Results obtained From NUMERICAL EXPERIMENTS}

Table 4 presents the feasible combination of the process parameters as determined by the RSM as well as the corresponding gas yield determined via the physical experiments. Figure 3 then presents the plots of the actual and predicted yield of the produced gas. The essence of the numerical experiments is to search for the optimum process condition that will ensure process efficiency and increase in the yield of the producer gas.

From Table 4, the combination of the process parameters that leads to the highest yield of gas $\left(2.55 \mathrm{Nm}^{3} / \mathrm{kg}\right)$ can be seen: temperature $\left(100^{\circ} \mathrm{C}\right)$, particle size $(6.00 \mathrm{~mm})$ and residence time $(35 \mathrm{~min})$.
From Figure 3 , it is obvious that there is a sound agreement between the yields of gas obtained from both the numerical and the physical experiments as indicated by the similarity of the patterns of the data points. This implies that the developed model is fit for a predictive purpose. The closeness of the values of the actual yields of gas obtained from the physical experiments and the predicted yield of gas from the numerical experiments means that the model is efficient and reliable. Under the similar process conditions, it could be used for the prediction of the yield of gas without the need for a physical experiment, which could be expensive and time consuming. Hence, this will assist the process designers in the determination of the throughput of the gasifier, given a certain input and process conditions.

Table 5 presents the statistical analysis of the developed quadratic model for predicting the yield of gas as a function of the independent process parameters, namely; temperature, particle size and residence 


\begin{tabular}{lccccc}
\hline Trials & $\begin{array}{c}\text { Factor A: } \\
\text { Temperature } \\
\left({ }^{\circ} \mathrm{C}\right)\end{array}$ & $\begin{array}{c}\text { Factor B: } \\
\text { Particle } \\
\text { size }(\mathrm{mm})\end{array}$ & $\begin{array}{c}\text { Factor C: } \\
\text { Residence } \\
\text { Time }(\mathrm{min})\end{array}$ & $\begin{array}{c}\text { Actual } \\
\text { gas yield } \\
\left(\mathrm{Nm}^{3} / \mathrm{kg}\right)\end{array}$ & $\begin{array}{c}\text { Predicted } \\
\text { gas yield } \\
\left(\mathrm{Nm}^{3} / \mathrm{kg}\right)\end{array}$ \\
\hline 1. & 900 & 6.00 & 35.00 & 2.00 & 1.9771 \\
2. & 800 & 10.00 & 60.00 & 1.80 & 1.7812 \\
3. & 800 & 2.00 & 10.00 & 1.20 & 1.2208 \\
4. & 1000 & 6.00 & 35.00 & 2.55 & 2.4804 \\
5. & 1200 & 2.00 & 10.00 & 1.80 & 1.8203 \\
6. & 1000 & 6.00 & 35.00 & 2.55 & 2.5540 \\
7. & 800 & 2.00 & 60.00 & 2.00 & 2.0347 \\
8. & 1000 & 8.00 & 35.00 & 2.43 & 2.4690 \\
9. & 1200 & 10.00 & 10.00 & 1.90 & 1.8560 \\
10. & 663.64 & 6.00 & 35.00 & 2.00 & 1.9899 \\
11. & 800 & 10.00 & 10.00 & 1.52 & 1.5589 \\
12. & 1200 & 10.00 & 60.00 & 1.99 & 2.0563 \\
13. & 1000 & 6.00 & 35.00 & 2.45 & 2.5657 \\
14. & 1200 & 2.00 & 60.00 & 2.22 & 2.3223 \\
15. & 1000 & 6.00 & 35.00 & 2.38 & 2.3789 \\
16. & 1000 & 1.00 & 35.00 & 1.77 & 1.7897 \\
17. & 1000 & 6.00 & 35.00 & 1.89 & 1.9043 \\
18. & 1000 & 6.00 & 55.00 & 2.50 & 2.5543 \\
19. & 1000 & 6.00 & 35.00 & 2.55 & 2.6097 \\
20. & 1000 & 6.00 & 30.00 & 2.47 & 2.5310 \\
\hline
\end{tabular}

TABLE 4. The results obtained from the numerical and physical experiments.

time, while Table 6 presents the Analysis of Variance (ANOVA) of the developed model.

The model "F-value" of 5.68 implies that the model is statistically significant. There is only a $0.60 \%$ chance that the model "F-value" this large could occur due to noise. In addition, the value of the "p-value Prob $>$ F" of the developed model was 0.0060 . The fact that the value of the "p-value Prob $>$ F" was less than 0.050 indicates that the model is statistically significant. The significant model terms which can greatly influence the yield of the gas are A (temperature), $\mathrm{C}$ (residence time) and $\mathrm{B}^{2}$ (a square of the particle size). The insignificant "Lack of Fit" value of 0.38 implies that the lack of fit is not statistically significant relative to the pure error. There is a $84.32 \%$ chance that a "Lack of Fit-F-value" this large could occur due to noise. "The insignificant Lack of Fit" value implies that the model is good for a predictive purpose. The values of the Adjusted R-squared (0.8892) and Predicted $\mathrm{R}$ squared (0.8840) are in a reasonable agreement with the $\mathrm{R}$ squared (0.8364), and were all close to 1 , thus, indicating that the model is suitable for correlative predictive purposes.

The results obtained from both the numerical and physical experiments were statistically analysed using the RSM to obtain a predictive model, which correlates the dependent variable (yield of the gas) as a function of the independent process parameters, namely temperature, particle size and residence time (Equation 21.

$$
\begin{aligned}
& \text { Yield of gas }=+2.40+0.18 A+6.984 E \\
& \quad-003 B+0.20 C-0.031 A B+0.071 A C \\
& \quad-0.11 B C-0.043 A^{2}-0.39 B^{2}-0.15 C^{2}
\end{aligned}
$$

Where $A$ is the temperature $\left({ }^{\circ} \mathrm{C}\right), B$ is the particle size $(\mathrm{mm})$ and $C$ is the residence time ( $\mathrm{min})$.

Figure 4 is the normal plot of residuals for the developed model for the yield of the produced gas.

The normal plot of the residuals depicts the degree of the normal distribution of the data set 38 . The closeness of the data set to the diagonal (average) line is an indication of the linearity of the residuals. This further indicates that the data set is approximately linear and normally distributed by approximation, although with an inherent randomness leftover within the error portion as shown in Figure 4

The variation of data points from the diagonal line were marginal within the permissible range of $\pm 10 \%$ in a relation to the average line without any outliner. This further indicates that the developed model is efficient and suitable for predictive and correlative purposes. This plot shows that there exists a close relationship between the actual and the predicted values of the yield of the gas as indicated by the closeness of the data points to the diagonal line.

Figures 5 and 6 shows the contour plot and the $3 \mathrm{D}$ plot of the effect of the temperature and particle size on the yield of gas, respectively. The operating temperature and particle size heavily influences the yield of the gas during the conversion process. This is because the char as well as the yield of tar and the subsequent gas product are a function of the combus- 


\begin{tabular}{lcccccc}
\hline $\begin{array}{l}\text { Statistical } \\
\text { parameters }\end{array}$ & $\begin{array}{c}\text { Sum of } \\
\text { Squares }\end{array}$ & df & Mean square & F value & $\begin{array}{c}\text { p-value } \\
\text { Prob }>\text { F }\end{array}$ & Remarks \\
\hline Model & 2.23 & 8 & 0.26 & 5.68 & 0.0060 & Significant \\
A-Temperature & 0.28 & 1 & 0.28 & 6.09 & 0.0332 & \\
B-Particle size & $4.212 \mathrm{E}-004$ & 1 & $4.212 \mathrm{E}-004$ & $9.230 \mathrm{E}-03$ & 0.9254 & \\
C-Residence time & 0.34 & 1 & 0.34 & 7.45 & 0.0212 & \\
AB & $7.813 \mathrm{E}-003$ & 1 & $7.813 \mathrm{E}-003$ & 0.17 & 0.6878 & \\
AC & 0.041 & 1 & 0.041 & 0.89 & 0.3677 & \\
BC & 0.090 & 1 & 0.090 & 1.98 & 0.1898 & \\
A2 & 0.011 & 1 & 0.01 & 0.24 & 0.6321 & \\
B2 & 0.36 & 1 & 0.36 & 7.95 & 0.0182 & \\
C2 & 0.038 & 1 & 0.038 & 0.83 & 0.3827 & \\
Residual & 0.032 & 10 & 0.032 & & & \\
Lack of Fit & 0.13 & 5 & 0.025 & 0.38 & 0.8432 & Not significant \\
Pure Error & 0.33 & 5 & 0.066 & & & \\
Corr. & 2.79 & 19 & & & & \\
\hline
\end{tabular}

TABLE 5. The statistical analysis of the developed model.

\begin{tabular}{lcc}
\hline Parameter & Value & Remarks \\
\hline R-Squared & 0.8364 & Significant \\
Adjusted R Squared & 0.8892 & Significant \\
Predicted R-Squared & 0.8840 & Significant \\
Adequate Precision & 8.2840 & Significant \\
\hline
\end{tabular}

TABLE 6 . The analysis of variance (anova) for the developed model.
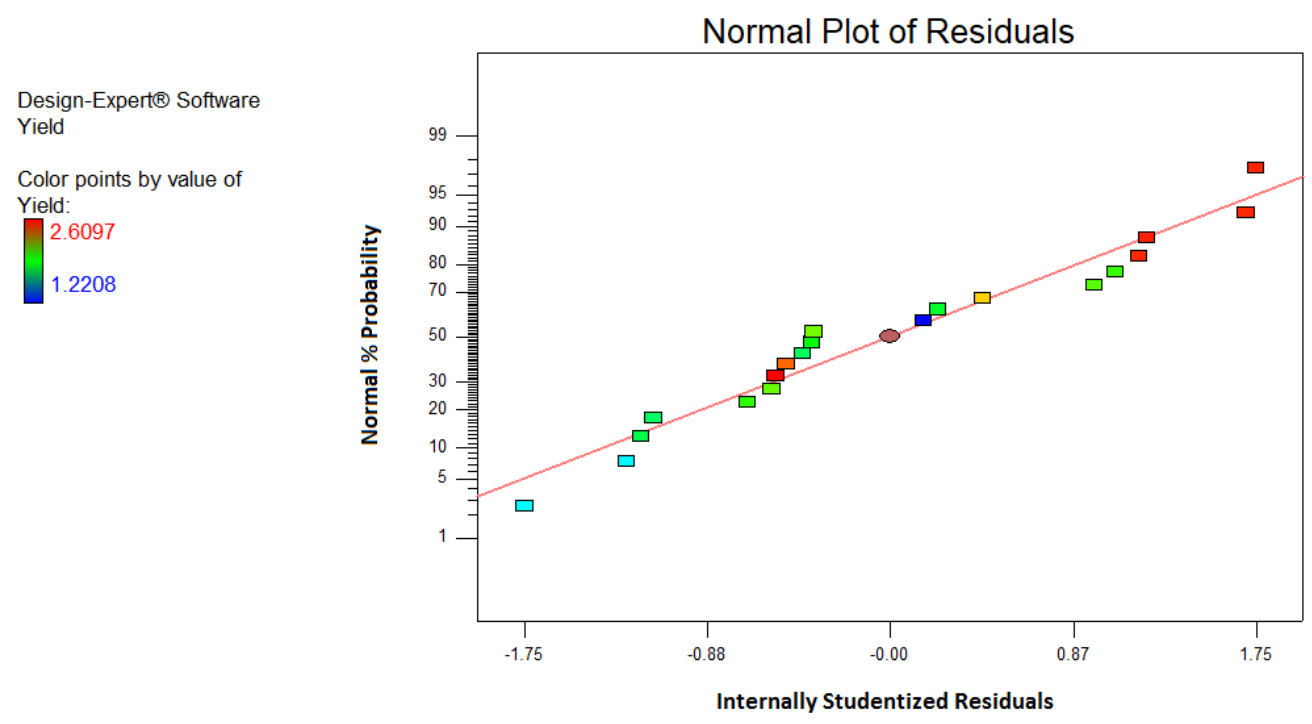

Figure 4. The normal plot of residuals . 


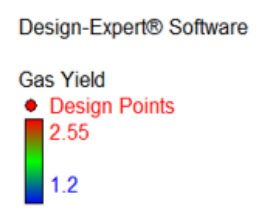

$\mathrm{X} 1=\mathrm{A}:$ Temperature X2 = B: Particle size

Actual Factor

C: Residece time $=35.00$

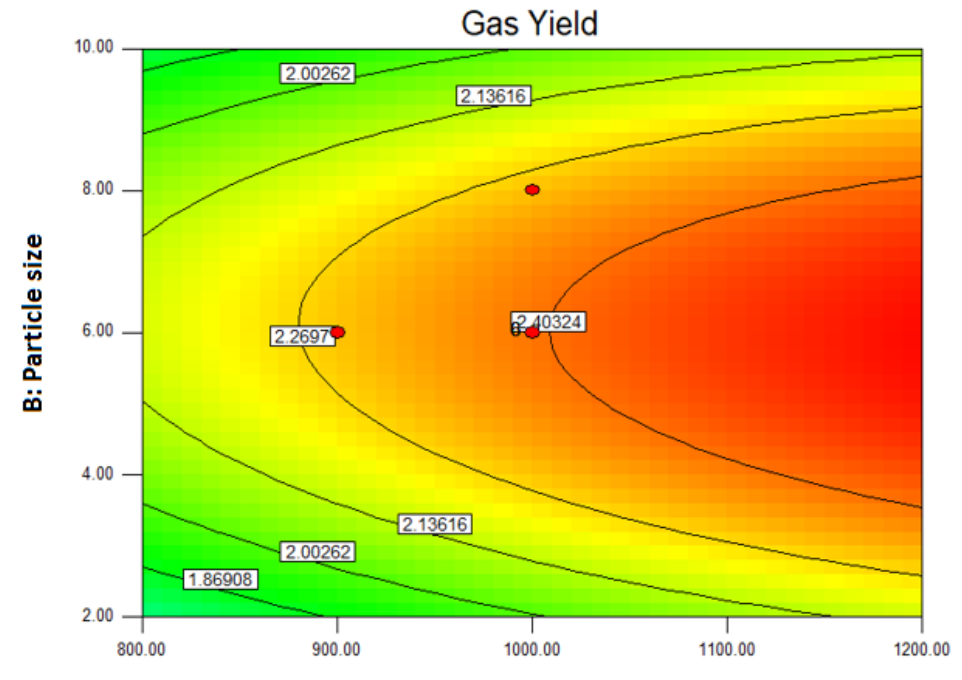

A: Temperature

Figure 5. The contour plot of the effect of the temperature and particle size on the yield of gas.

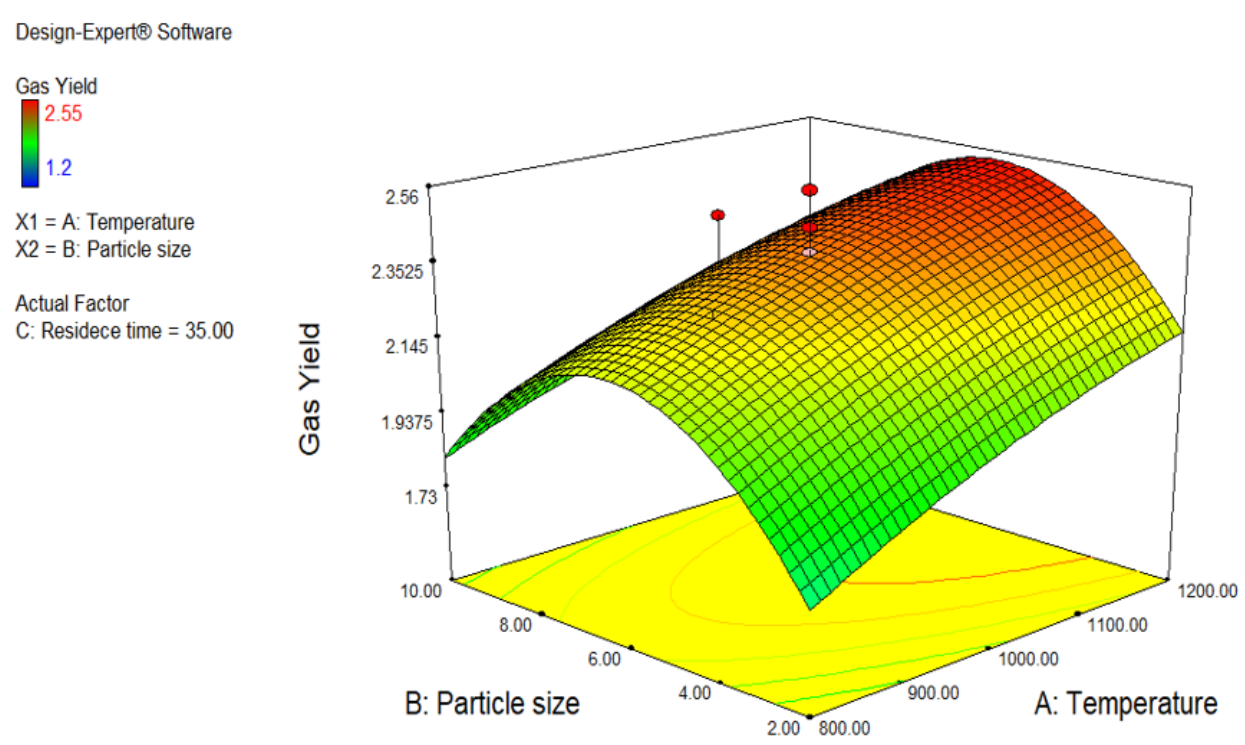

Figure 6 . The 3D plot of the effect of the temperature and particle size on the yield of gas.

tion temprerature. The rate of combustion of the char is also a function of its size and the operating temprature. From the plot, an increase in temperature to the optimum value favours the forward reaction resulting in a decrease in the tar and char content and vice versa. This is due to the fact that the amount of tar and char produced are converted to hydrogen gas, oxides of carbon and other light hydrocarbons via the process of thermal cracking as the operating temperature increases, thereby leading to the production of more gas. From Figures 5 and 6, as the temperature increases, further reduction in the amount of tar can be observed, but with an increase in the content of hydrogen gas and a reduction in the amount of oxides of carbon oxide. This increases the amount of the producer gas, thereby making the gaisifer more environmental-friendly. The range of the temperature distribution during the conversion process was also observed to vary from $800-1200{ }^{\circ} \mathrm{C}$. The initial low temperature can be traced to the presence of some volatile matters in the biomass. However, a progressive increase in the magnitude of the temperature was observed as the conversion process proceeded with time. The gas yield was also observed to increase from $1.86908 \mathrm{Nm}^{3} / \mathrm{kg}$ to $2.40324 \mathrm{Nm}^{3} / \mathrm{kg}$ as the temperature increased from $800-1200{ }^{\circ} \mathrm{C}$ at a residence time of 35 mins. This finding strongly agrees with the findings of many researchers as reported by the literature [22, 34, 40,42. Li et al. [22] explain the significance of the operating temperature during the conversion of biomass to fuel. In an agreement with the findings of this study, the authors reported that an increase in the temperature enhances the biomass combustion, but with an increase in the time required 


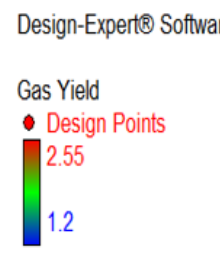

$\mathrm{X} 1=\mathrm{A}:$ Temperature $\mathrm{X} 2=\mathrm{C}$ : Residece time

Actual Factor B: Particle size $=6.00$

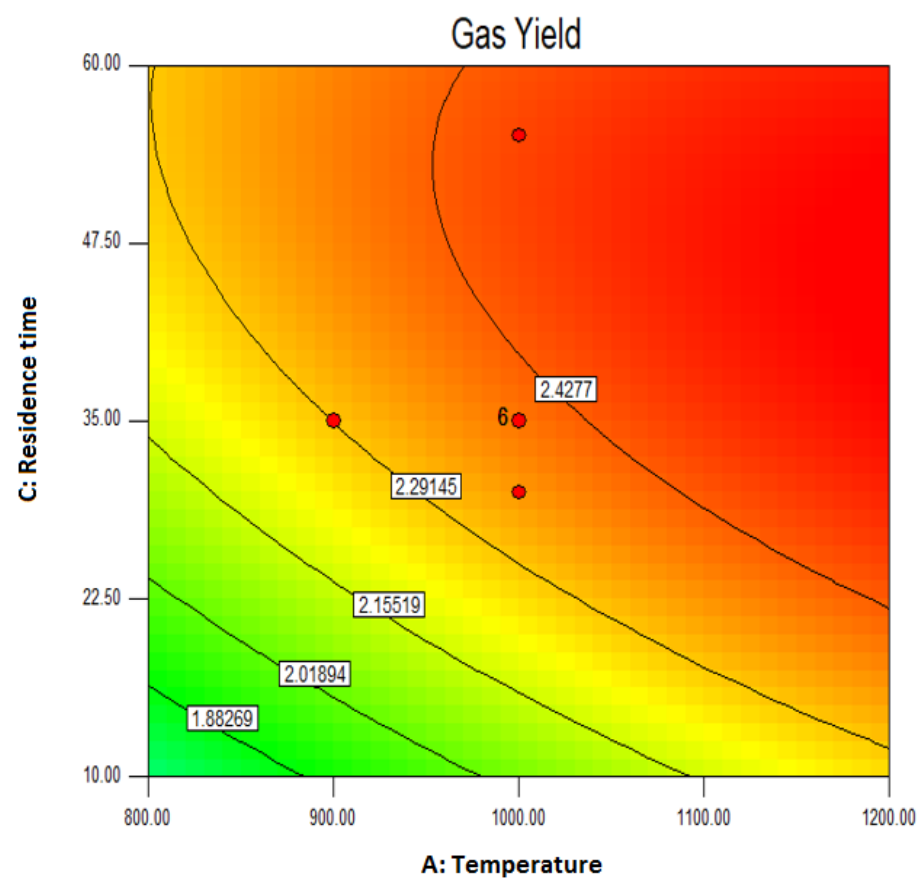

FiguRE 7. The contour plot of the effect of the temperature and residence time on the yield of gas.
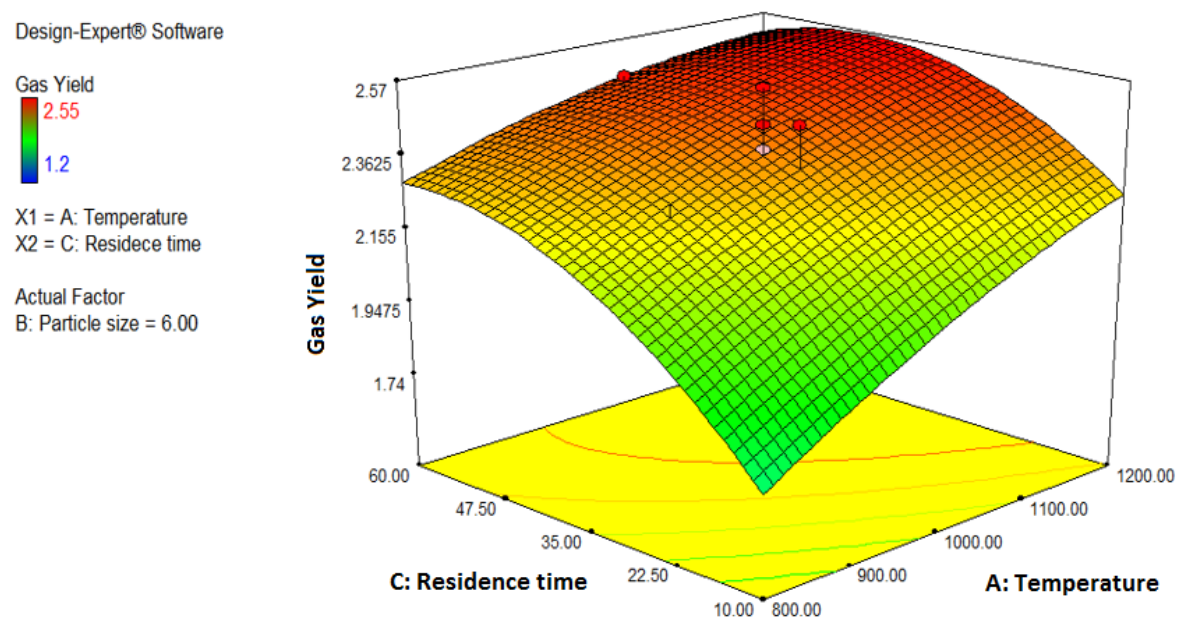

Figure 8 . The 3D plot of the effect of the temperature and residence time on the yield of gas.

to burn out the char completely. Hence, the higher the temperature, the higher the rate of biomass combustion, but with an increase in the residence time. However, the magnitude of temperature increases with an increase in the energy requirement of the process. This can make the process less sustainable in terms of energy consumption and environmental sustainability. In addition, an increase in the magnitude of the temperature beyond the optimum promotes the possibility for a slag formation, thereby making the conversion process less sutainable. As the temperature increases, the particle size decreases and vice versa. This is in line with the findings of $\mathrm{Lu}$ et al. [7, who established that the particle size significantly affects the dynamics of the biomass particle, including the drying, heating and reaction rates. The authors reported an inverse relationship between the particle size and the drying, heating as well as reaction rates, which are a function of the operating temperature.

Figures 7 and 8 show the contour plot and the interactive $3 \mathrm{D}$ plot of the effect of the temperature and residence time on the gas yield, respectively. From Figures 7 and 8 , an increase in the magnitude of time and temperature was observed to promote the forward reaction, thereby resulting in a high yield of the producer gas. This also agrees with the findings of $\mathrm{Li}$ et al. 22 that a direct relationship exists between the temperature and residence time during the conversion of biomass to fuel. The yield of the producer gas ranges from a minimum value of 1.88269 to a maximum value of $2.4277 \mathrm{Nm}^{3} / \mathrm{kg}$ as the residence time increases from $10 \mathrm{~min}$. to $60 \mathrm{~min}$. and combustion 


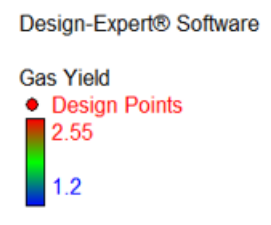

X1 = B: Particle size X2 = C: Residece time

Actual Factor A: Temperature $=1000.00$

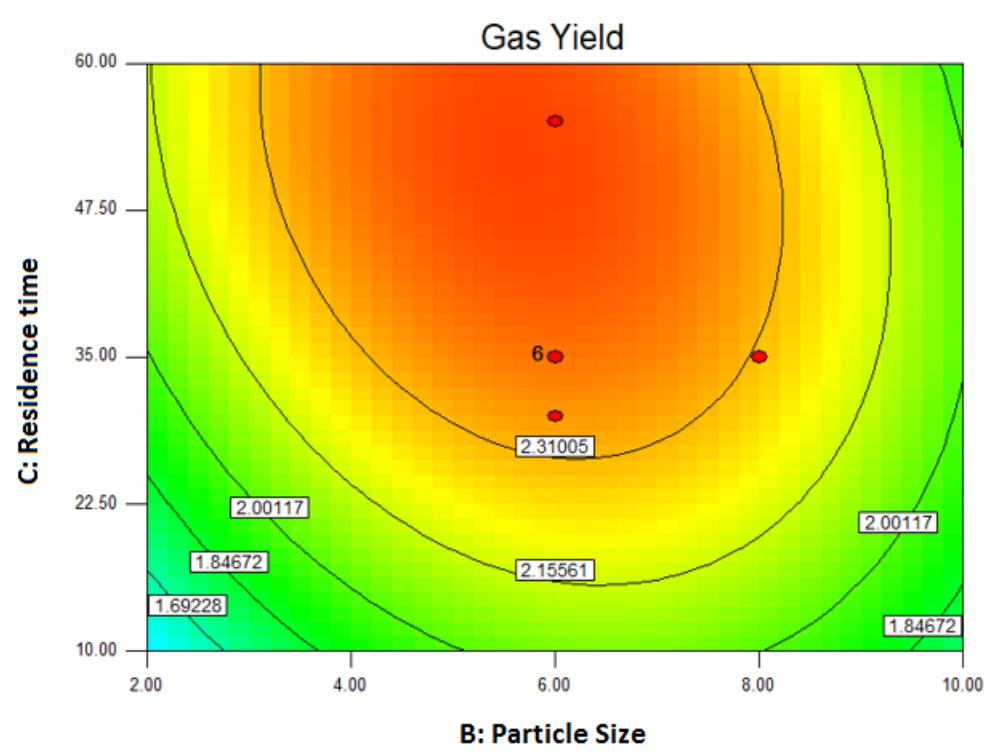

Figure 9. The contour plot of the effect of the particle size and residence time on the yield of gas.

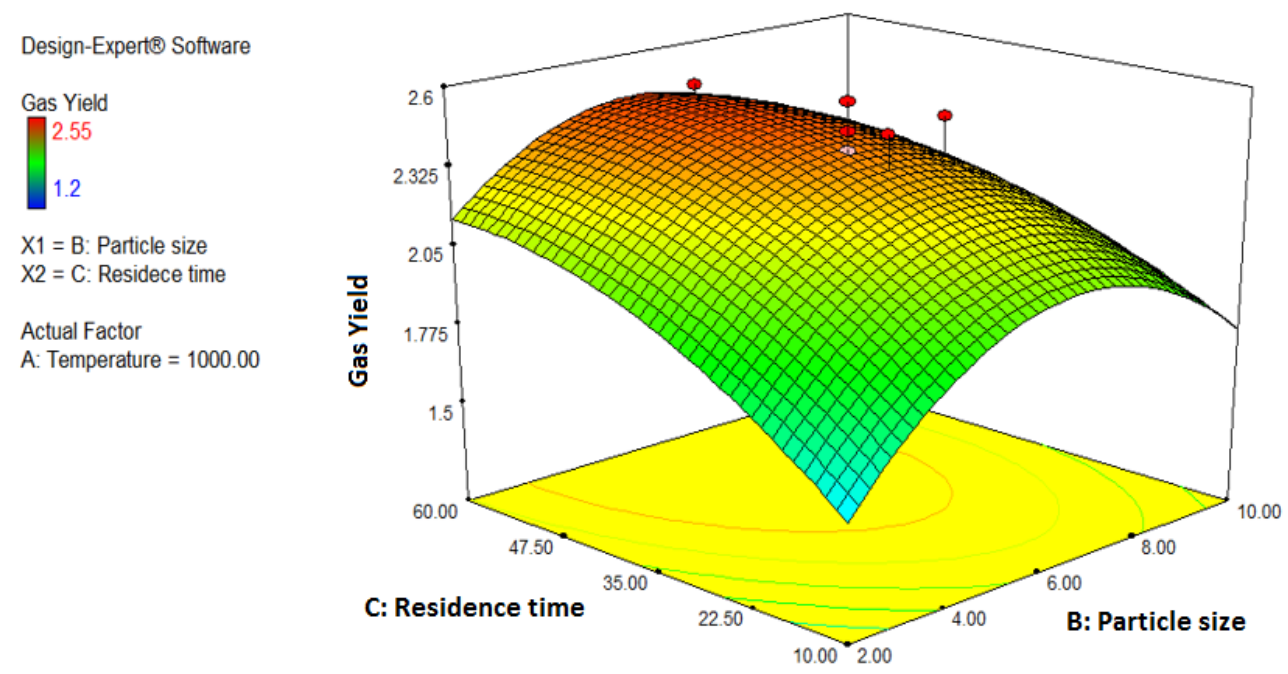

Figure 10. The 3D plot of the effect of the particle size and residence time on the yield of gas.

temperature from $800{ }^{\circ} \mathrm{C}$ to $1200{ }^{\circ} \mathrm{C}$. The relationship among the tar content, time and the temperature was observed to be inversely proportional. Hence an increase in the magnitude of the residence time and combustion temperature results in a decreasing content of the tar and vice versa. This confirms the fact that a sufficient time is needed to drive the conversion process to the required completion. A lower residence time may promote the incomplete combustion of the biomass constituents, thereby resulting in lower yields of the producer gas and vice versa. The obtained results indicate that an optimum residence time of $35 \mathrm{~min}$. was sufficient for the conversion process. A further increase beyond this time may lead to a decrease in the tar content and a low rate of conversion of biomass to gas at high energy input, thereby making the process less sustainable.

Figures 9 and 10 show the contour plot and the interactive $3 \mathrm{D}$ plot of the effect of the particle size and residence time on the gas yield, respectively. A direct relationship was observed between the yield of the gas and the residence time. At first, an increase in the size of the particle size was observed to increase the yield of the gas up to the size of $6 \mathrm{~mm}$. A further increase in the size of the particle beyond this value promotes the backward reaction resulting in the reduction in the yield of the gas produced. This relates to the fact that as the particle sizes increases, beyond the optimum, the rate of combustion will decrease due to a lesser interaction of the biomass constituents with other elements thereby slowing down the rate of conversion rate and vice versa. The smaller the particle sizes, the larger the area to volume ratio of the wood particle and the rate of reaction and production rate of the producer gas is and vice versa and [22, 43, 44]. 


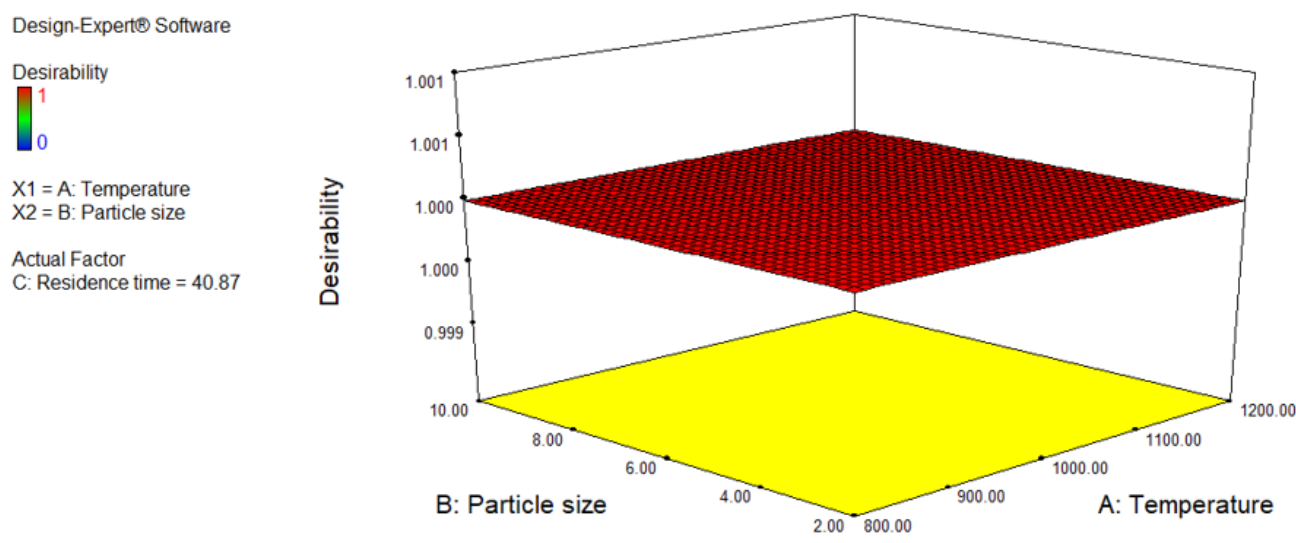

FIgURE 11. The desirability plot for the optimization of the process parameters.

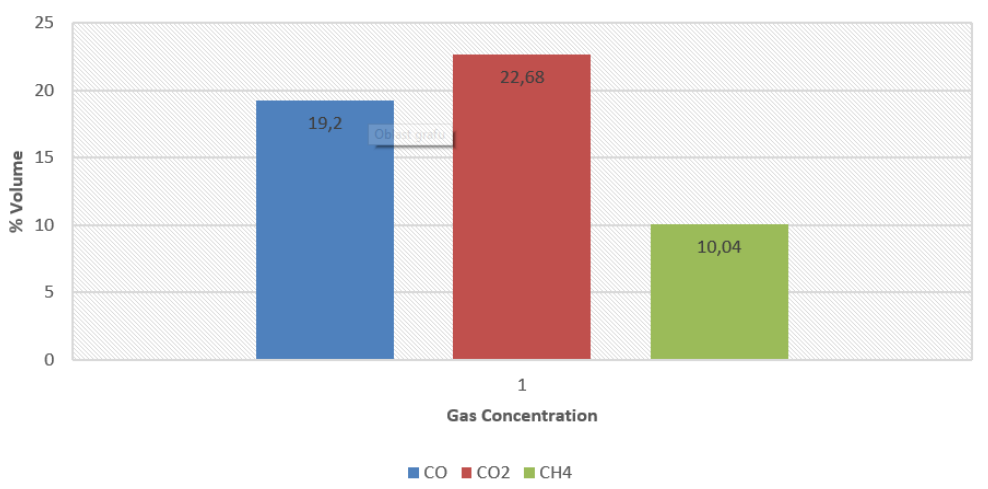

Figure 12. Comparison of the \% volume of the gas concentration.

\subsection{NUMERICAL OPTIMIZATION OF THE PROCESS PARAMETERS}

The numerical optimization of the process parameters was carried using the Design Expert software. With the goal of maximizing the yield of the producer gas, the optimization produced 30 feasible solutions whose desirability equals to 1 , as shown in Figure 11. The closer the desirability value is to 1 , the more desirable the responses obtained are. The fact that the desirability value equals to 1 implies that the optimum values of yield and process parameters obtained are highly desirable. The optimum process parameters that produced the highest rate of conversion of biomass to energy $\left(2.50694 \mathrm{Nm}^{3} / \mathrm{kg}\right)$ during the numerical optimization were: temperature $\left(1082.40^{\circ} \mathrm{C}\right)$, particle size $(6.16 \mathrm{~mm})$ and residence time $(40.87 \mathrm{~min})$. Comparing these optimal values to the optimal values obtained via the physical experimentats: energy yield $\left(2.55 \mathrm{Nm}^{3} / \mathrm{kg}\right)$, temperature $\left(1000^{\circ} \mathrm{C}\right)$, particle size $(6.0 \mathrm{~mm})$ and residence time $(35 \mathrm{~min})$, it is obvious that the range of the process parameters for the numerical optimization and physical experiments were close. This further lends confirms the fact that the developed model is highly efficient for correlative and predictive purposes.

\subsection{Results OBTAINED FROM THE ANALYSIS OF THE CONCENTRATION OF THE GAS PRODUCED}

Table 7 and Figure 12 show the volume percentage of the concentration of the gas produced. The combustible gas generated with the present experimental setup contains only methane, carbon monoxide and carbon dioxide as the major constituents. Hence, only they are considered in the analysis. Figure 11 shows that there is a need for further removal of tar from the produced gas. The amount of carbon oxide present in the gas was the highest ( $19.20 \%$ by volume), which is significant enough to cause health risks and environmental pollution. Carbon oxide is a poisonous gas, which can cause serious health problems, when inhaled [23]. In addition, the amount of carbon dioxide was also significant ( $22.68 \%$ by volume). Carbon dioxide is a greenhouse gas capable of causing global warming, thereby making the use of the producer gas less sustainable and less environmentally friendly. Although the composition of the methane gas obtained was satisfying ( $10.04 \%$ by volume), an even higher yield can be obtained via an adequate process design and effective reduction in the tar content of the intermediate product during the process of conversion. 


\begin{tabular}{lc}
\hline Concentration & $\%$ (Vol.) \\
\hline $\mathrm{CO}$ & 19.20 \\
$\mathrm{CO}_{2}$ & 22.68 \\
$\mathrm{CH}_{4}$ & 10.04 \\
\hline
\end{tabular}

TABLE 7. Concentration of the produced gas.

\section{Conclusion}

The process optimization and performance evaluation of a downdraft gasifier suitable for energy generation using wood biomass was carried out in this study in the effort to develop renewable and alternative sources of a clean and safe energy. The obtained results indicated that the downdraft gasifier can convert wood chips to producer gas for the generation of energy for light to medium duty. The analysis of the gas concentration indicated a satisfying generation of the methane gas, but with a significant amount of $\mathrm{CO}$ and $\mathrm{CO}_{2}$. This implies the need for an effective process of tar removal in order to ensure that the production of gas is safe and environmentally sustainable. Using the RSM, the optimum process parameters that produced the highest rate of conversion of biomass to energy $\left(2.55 \mathrm{Nm}^{3} / \mathrm{kg}\right)$ were found to be: temperature $\left(1000^{\circ} \mathrm{C}\right)$, particle size $(6.0 \mathrm{~mm})$ and residence time ( $35 \mathrm{~min}$ ). In addition, the developed and statistically validated mathematical model showed a capacity for predicting the yield of the producer gas. The produced gas contained a satisfying amount of methane gas $(10.04 \%$ vol.), but with a significant amount of $\mathrm{CO}(19.20 \%$ vol. $)$ and $\mathrm{CO}_{2}(22.68 \%$ vol. $)$. From the numerical results obtained, the gas yield was observed to increase from $1.86908 \mathrm{Nm}^{3} / \mathrm{kg}$ to $2.40324 \mathrm{Nm}^{3} / \mathrm{kg}$ as the temperature increased from $800-1200,{ }^{\circ} \mathrm{C}$. The results obtained indicate the feasibility of the production of combustible gas from the developed system using wood chips. The combustible gas generated with the present experimental setup contains only methane, carbon monoxide and carbon dioxide as the major constituents. Hence, only they are considered in the analysis.

It is, therefore, recommended that governments of many countries who still largely rely on the traditional energy generation via biomass should embrace this innovation and put the appropriate policies in place to encourage its use. A future research can consider a deeper performance evaluation of the downdraft gasifier.

\section{REFERENCES}

[1] H. Lu, W. Robert, G. Peirce, et al. Comprehensive study of biomass particle combustion. Energy Fuels 22(4):2826-2839, 2008. https://doi.org/10.1021/ef800006z

[2] I. A. Daniyan, A. K. Ahwin, A. A. Aderoba, O. L. Daniyan. Development of a smart digester for the production of biogas. Petroleum and Coal 60(5):804-821, 2018.
[3] I. A. Daniyan, K. A. Ahwin, A. A. Aderoba, et al. Development and optimization of a smart digester for the production of biogas. In Proceedings of the International Conference on Industrial Engineering and Operations Management Pretoria/Johannesburg, South Africa, October 29 - November 1, pp. 1456-1459. 2018.

[4] A. Sahir. Qureshi specific concerns of Pakistan in the context of energy security issues and geopolitics of the region. Energy Policy 35(4):2031-2037, 2007. https://doi.org/10.1016/j.enpol.2006.08.010

[5] P. S. C. Rao, J. B. Miller, Y. D. Wang, J. B. Byrne. Energy-microfinance intervention for below poverty line households in India. Energy Policy 37(5):1694-1712, 2009 .

https://doi.org/10.1016/j.enpol.2008.12.039

[6] S. Gorjian. An introduction to renewable energy technologies. [2021-03-04], https://doi.org/10.13140/RG.2.2.27055.53928

[7] H. Lu, E. Ip, J. Scott, et al. Effects of particle shape and size on devolatilization of biomass particle. Fuel 89(5):1156-1168, 2010.

https://doi.org/10.1016/j.fuel.2008.10.023

[8] G. Tucho, S. Nonhebel. Bio-wastes as an alternative household cooking energy source in Ethiopia. Energies 8(9):9565-9583, 2015.

https://doi.org/10.3390/en8099565

[9] V. Tumwesige, G. Okello, S. Semple, J. Smith. Impact of partial fuel switch on household air pollutants in sub-Sahara Africa. Environmental Pollution 231(1):1021-1029, 2017. https://doi.org/10.1016/j.envpol.2017.08.118.

[10] I. Ozturk, F. Bilgili. Economic growth and biomass consumption nexus: dynamic panel analysis for Sub-Sahara African countries. Applied Energy 137:110-116, 2015. https://doi.org/10.1016/j.apenergy.2014.10.017

[11] K. Mortimer, C. B. Ndamala, A. W. Naunje, et al. A cleaner burning biomass-fuelled cook stove intervention to prevent pneumonia in children under 5 years old in rural Malawi (the Cooking and Pneumonia Study): a cluster randomised controlled trial. Lancet 389(10065):P167-175, 2017. https ://doi.org/10.1016/S0140-6736(16)32507-7

[12] A. K. Chatterjee. State of the Art Report on Pyrolysis of Wood and Agricultural Biomass. U.S. Department of Agriculture, Newark, NJ, 2014. PN AAK-818, https://www.osti.gov/biblio/6043806.

[13] J. Saastamoinen, M. Aho, A. Moilanen, et al. Burnout of pulverized biomass particles in large scale boiler - single particle model approach. Biomass Bioenergy 34(5):728-736, 2010. https://doi.org/10.1016/j.biombioe.2010.01.015 
[14] J. J. Hernández, G. Aranda, J. Barba, J. M. Mendoza. Effect of steam content in the air-steam flow on biomass entrained flow gasification. Fuel Processing Technology 99:43-55, 2012. https://doi.org/10.1016/j.fuproc.2012.01.030.

[15] T. Song, J. Wu, L. Shen, J. Xiao. Experimental investigation on hydrogen production from biomass gasification in interconnected fluidized beds. Biomass Bioenergy 36:258-267, 2012. https://doi.org/10.1016/j.biombioe.2011.10.021

[16] P. Mondal, G. S. Dang, M. O. Garg. Syngas production through gasification and clean-up for downstream applications - recent developments. Fuel Processing Technology 92(8):1395-1410, 2011. https://doi.org/10.1016/j.fuproc.2011.03.021.

[17] E. E. Donath. Vehicle gas producers. Fuel Processing Technology 3(2):141-153, 1980. https://doi.org/10.1016/0378-3820(80)90017-X.

[18] S. Chakrabarty, F. M. Boksh, A. Chakraborty. Economic viability of biogas and green self-employment opportunities. Renewable and Sustainable Energy Reviews 39:757-766, 2013. https://doi.org/10.1016/j.rser.2013.08.002

[19] M. K. Sidhu, K. Ravindra, S. Mor, S. John. Household air pollution from various types of rural kitchens and its exposure assessment. Science of The Total Environment 586:419-429, 2017. https://doi.org/10.1016/j.scitotenv.2017.01.051.

[20] T. R. Reed, D. Jantzen. Generator Gas: The Swedish Experience from 2009-2014 (a translation of the Swedish book, Gengas). Solar Energy Research Institute, Golden, CO, 2012. SERI/SP-33-140.

[21] S. C. Saxena, J. C. K. Fluidized-bed incineration of waste materials. Progress in Energy and Combustion Science 20(4):281-324, 1994. https : //doi.org/10.1016/0360-1285(94) 90012-4.

[22] J. Li, C. P. Manosh, P. L. Younger, et al. Prediction of high-temperature rapid combustion behaviour of woody biomass particles. Fuel 165:205-214, 2016. https://doi.org/10.1016/j.fuel.2015.10.061

[23] P. McKendry. Energy production from biomass (part 1): Overview of biomass. Bioresource Technology 83(1):37-46, 2002. https://doi.org/10.1016/S0960-8524(01)00118-3

[24] A. Kumaraswamy, B. D. Prasad. Performance analysis of a dual fuel engine using LPG and diesel with EGR system. Procedia Engineering 38:2784-2792, 2012. https://doi.org/10.1016/j.proeng.2012.06.326.

[25] T. B. Reed. A Survey of Biomass Gasification, Vol. I Synopsis and Executive Summary. Solar Energy Research Institute, Golden, CO, 2011. SERI/TR-33-239 (Vol. I).

[26] S. Chinguwa, W. R. Nyemba, T. C. Jen.

Development and fabrication of a wood gasifier to power an internal combustion engine. In Proceedings of the International Conference on Industrial Engineering and Operations Management Pretoria/Johannesburg, South Africa, October 29 - November 1, pp. 537-547. 2018.

[27] N. A. Inglea, S. S. Lakade. Design and development of downdraft gasifier to generate producer gas. Energy Procedia 90:423-431, 2016.

https://doi.org/10.1016/j.egypro.2016.11.209.
[28] M. A. Masmoudi, M. Sahraoui, N. Grioui,

K. Halouani. 2-D modeling of thermo-kinetics coupled with heat and mass transfer in the reduction zone of a fixed bed downdraft biomass gasifier. Renewable Energy 66:288-298, 2014.

https://doi.org/10.1016/j.renene.2013.12.016.

[29] N. Striugas, K. Zakarauskas, A. Dziugys, et al. An evaluation of performance of automatically operated multi-fuel downdraft gasifier for energy production. Applied Thermal Engineering 73(1):1151-1159, 2014. https:

//doi.org/10.1016/j.applthermaleng.2014.09.007.

[30] J. Reeb, M. Milota. Moisture content by the oven-dry method for industrial testing. Oregon State University, Corvallis, OR, pp. 1-9.

[31] Manual for design calculation of downdraught gasifier. [2021-03-04], https://www.fao.org/3/T0512E/T0512e1a.htm.

[32] F. Pinto, C. Franco, R. N. André, et al. Cogasification study of biomass mixed with plastic wastes. Fuel 81(3):291-297, 2002. https://doi.org/10.1016/S0016-2361(01)00164-8

[33] C. Franco, F. Pinto, I. Gulyurtlu, I. Cabrita. The study of reactions influencing the biomass steam gasification process. Fuel 82(7):835-842, 2003. https://doi.org/10.1016/S0016-2361(02)00313-7.

[34] L. E. Taba, M. F. Irfan, W. A. M. Wan Daud, M. H. Chakrabarti. The effect of temperature on various parameters in coal, biomass and CO-gasification: A review. Renewable and Sustainable Energy Reviews 16(8):5584-5596, 2012. https://doi.org/10.1016/j.rser.2012.06.015

[35] G. Sharma, M. V. S. Krishna. Performance evaluation of high pressure down draft biomass gasifier for BIG/GT applications. International Journal of Engineering Research 5(2):499-505, 2016. https://doi.org/10.17950/ijer/v5i2/044.

[36] A. K. Chatterjee. State of the Art Report on Pyrolysis of Wood and Agricultural Biomass. U.S. Department of Agriculture, Newark, NJ., 2014. PN - AAK-818.

[37] I. A. Daniyan, K. Mpofu, A. O. Adeodu, O. Momoh. Development and automation of a $12 \mathrm{~kW}$-capacity gasifier for energy generation. In 2020 Southern African Universities Power Engineering Conference/Robotics and Mechatronics/Pattern Recognition Association of South Africa (SAUPEC/RobMech/PRASA). Added to IEEE Xplore, pp. 68-73. 2020. https://doi.org/10. 1109/SAUPEC/RobMech/PRASA48453.2020.9040963.

[38] I. A. Daniyan, I. Thabadira, K. Mpofu, A. O. Adeodu. Development of numerical models for the prediction of temperature and surface roughness during the machining operation of titanium alloy (Ti6Al14V). Acta Polytechnica 60(5):369-390, 2020. https://doi.org/10.14311/AP.2020.60.0369

[39] I. A. Daniyan, F. Fameso, F. Ale, et al. Modelling, simulation and experimental validation of the milling operation of titanium alloy (Ti6Al4V). The International Journal of Advanced Manufacturing Technology 109(7):1853-1866, 2020. https://doi.org/10.1007/s00170-020-05714-y 
[40] T. Y. Ahmed, M. M. Ahmad, S. Yusup, et al. Mathematical and computational approaches for design of biomass gasification for hydrogen production: A review. Renewable and Sustainable Energy Reviews 16(4):2304-2315, 2012.

https://doi.org/10.1016/j.rser.2012.01.035

[41] D. A. Bulushev, J. R. H. Ross. Catalysis for conversion of biomass to fuels via pyrolysis and gasification: a review. Catalysis Today 171(1):1-13, 2011. https://doi.org/10.1016/j.cattod.2011.02.005.

[42] J. P. Stratford, T. R. Hutchings, F. A. A. M. de Leij. Intrinsic activation: The relationship between biomass inorganic content and porosity formation during pyrolysis. Bioresource Technology 159(5):104-111, 2014. https://doi.org/10.1016/j.biortech.2014.02.064.

[43] C. Zhang. Numerical modeling of coal gasification in an entrained-flow gasifier. In ASME 2012 International Mechanical Engineering Congress and Exposition, vol. 6, p. 1193-1203. 2012. https://doi.org/10.1115/IMECE2012-88481

[44] J. J. Hernández, G. Aranda-Almansa, A. Bula. Gasification of biomass wastes in an entrained flow gasifier: Effect of the particle size and the residence time. Fuel Processing Technology 91(6):681-692, 2010. https://doi.org/10.1016/j.fuproc.2010.01.018. 